\title{
Biomechanical comparison of tenodesis reconstruction for subtalar instability: a finite element analysis
}

\author{
Xu Can, Li Mingqing, Wang Chenggong and Liu Hua*
}

\begin{abstract}
Background: There are several types of tenodesis reconstruction designed for subtalar instability. However, no comprehensive comparison has been conducted among these procedures in terms of their correcting power so far. The objective of this study is to evaluate the biomechanical behaviors of 5 representative procedures through finite element analysis.

Methods: Finite element models were established and validated based on one of our previous studies. The Pisani interosseous talocalcaneal ligament (ITCL) reconstruction, Schon cervical ligament (CL) reconstruction and Choisne calcaneofibular ligament (CFL) reconstruction were compared on the model with the CFL, ITCL and CL sectioned. The Schon triligamentous reconstruction and Mann triligamentous reconstruction were compared on the model with the CFL, ITCL and CL, as well as the ATFL sectioned. The inversion and external/internal rotation were quantified at different ankle positions based on the rotational moment. Then, the stress in ligaments and reconstructed grafts and the contact characteristics of the subtalar joint under inversional stress test were calculated and compared accordingly.
\end{abstract}

Results: For single ligament reconstruction, the Choisne CFL reconstruction provided the greatest degree of correction for subtalar instability, followed by the Schon $\mathrm{CL}$ reconstruction and then the Pisani ITCL reconstruction. For triligamentous reconstruction, the Mann procedure outperformed the Schon procedure in alleviating the subtalar instability.

Conclusion: The finite element analysis showed that the Choisne CFL reconstruction and Mann triligamentous reconstruction provided the greatest degree of immediate postoperative subtalar stability. However, both procedures could not restore the biomechanical behaviors of the subtalar joint to normal. The long-term efficacy of these procedures warrants further investigation using a substantially larger sample of clinical cases.

Keywords: Finite element, Subtalar instability, Tenodesis reconstruction, Biomechanical, Kinematic characteristics

\section{Introduction}

Subtalar instability is a common functional talocalcaneal instability always coupled with lateral ankle instability. It was reported that about $10-25 \%$ of patients with lateral ankle instability suffered from subtalar instability $[1,2]$.

\footnotetext{
*Correspondence: liuhua345@163.com

Department of Orthopaedics, Xiangya Hospital, Central South University, No. 87, Xiangya Road, Changsha 410008, China
}

Subtalar instability mainly results in varus tilt and anterior translation of the calcaneus. However, its clinical manifestation is often covered by the lateral ankle instability, for which, it is only recognized as a separate clinical condition that needs specific treatment in recent years [3].

The exact aetiology of subtalar instability is still unknown. Several cadaveric studies reported that the main

C The Author(s). 2020 Open Access This article is licensed under a Creative Commons Attribution 4.0 International License, which permits use, sharing, adaptation, distribution and reproduction in any medium or format, as long as you give appropriate credit to the original author(s) and the source, provide a link to the Creative Commons licence, and indicate if changes were made. The images or other third party material in this article are included in the article's Creative Commons licence, unless indicated otherwise in a credit line to the material. If material is not included in the article's Creative Commons licence and your intended use is not permitted by statutory regulation or exceeds the permitted use, you will need to obtain permission directly from the copyright holder. To view a copy of this licence, visit http://creativecommons.org/licenses/by/4.0/ The Creative Commons Public Domain Dedication waiver (http://creativecommons.org/publicdomain/zero/1.0/) applies to the data made available in this article, unless otherwise stated in a credit line to the data. 
ligaments which stabilize the subtalar joint were the calcaneofibular ligament (CFL), the interosseous talocalcaneal ligament (ITCL) and the cervical ligament (CL) [4-7]. For chronic subtalar instability, conservative therapies such as proprioceptive training, stretching of the Achilles tendon, and prescription of orthosis are the primary treatment. When these conservative treatments fail, surgery is indicated. The earlier operation adopted for subtalar instability was duplicated from the procedures for stabilizing the lateral ankle. Most of them, such as the Elmslie [8], Chrisman-Snook [9] and Watson-Jones [10] procedures, attempt to recreate the CFL and anterior talofibular ligament (ATFL). Theoretically, CFL recreation is effective in stabilizing the subtalar joint because the CFL can bridge the posterior facet of the subtalar joint. However, the ITCL and CL, which play an important role in subtalar stability, were not recreated in these approaches.

Therefore, new procedures including the Pisani ITCL reconstruction [11], Schon CL reconstruction [12], Choisne CFL reconstruction [13], Schon triligamentous reconstruction [12] and Mann triligamentous reconstruction [14] were developed.

Any procedures for joint stabilization should be evaluated for biomechanical effectiveness. The goal of these tenodesis reconstructions is generally to mimic the functions of ligaments as far as possible. To the best of our knowledge, for these newly developed tenodesis procedures, their effects in stabilizing the subtalar joint have not been compared before.

Some cadaver studies have evaluated the effects of different ligaments in stabilizing the subtalar joint [4-7]. However, to compare these different types of tenodesis reconstruction, the cadavers to be tested should be strictly the same in terms of their material properties and morphologies, in order to ensure the comparability of the experimental results. Unfortunately, a cadaveric model could be used for only two or three times for the bony framework between each bone tunnels would be unstable after repeated use. The finite element analysis (FEA) is a reliable tool for the quantitative evaluation of biomechanical performance. By using FEA, one model can be tested on the basis of the same material properties and morphologies under several different loading settings. Moreover, FEA can also derive a number of invaluable outputs such as the contact pressure and internal stress, and therefore, it is useful for preoperative planning and surgery assessment. Referencing to a previous study [15], an FE model of the foot and ankle containing 28 bones (tibia, fibula and $26 \mathrm{ft}$ bones), sesamoids, plantar fascia, 24 main ligaments, and cartilage was developed and used to compare 5 different tenodesis reconstructions over their biomechanical behaviors. The goal of this study is to provide reference for the optimal design of subtalar stabilization.

\section{Methods \\ Model development}

An FE model of subtalar instability was developed based on one of our previous studies [15] (Fig. 1). CT scans of the foot and ankle at $0.5 \mathrm{~mm}$ intervals of a healthy male adult volunteer (30 years old with a height of $170 \mathrm{~cm}$ and a weight of $68 \mathrm{~kg}$ ) were used to develop bony structures. The bony structures were meshed with rigid surface elements in view of their small strain compared to soft structures. The magnetic resonance imaging (MRI) scans were used to develop the soft tissue geometry, including ligaments and cartilage. Ligaments were added manually into the $3 \mathrm{D}$ models. The insertion and the original site were identified by MRI presentations while referencing to previous journal papers and textbooks $[16,17]$. Then, the ligaments of hindfoot and midfoot (24 ligaments) were added into the model. The link element was used for the ligament. The nodes of the link element and the bone were merged together. The cartilages of tibiotalar, subtalar, talonavicular and calcaneocuboid joints were identified on T1-weight MRI images. Their geometries were generated first and then incorporated to the joints and meshed.

The ligaments of the tibia and fibula were assigned with non-linear force-displacement equations [18]. The material properties were expressed as curve fit data (a and b) for an elastic force-strain response function $\left(\mathrm{T}(\varepsilon)=\mathrm{a}\left(\mathrm{e}^{\mathrm{b} \varepsilon}-1\right)\right)$. The tibionavicular ligament was assigned with a linear stiffness $\mathrm{k}$, which was provided [19] (Table 1). The mechanical properties of the hindfoot and midfoot ligaments were assumed to be equal to the ATFL and scaled by their relative cross-sectional areas. The ATFL had a cross-sectional area of $62.85 \mathrm{~mm}^{2}$ [19], and the areas for other ligaments were provided by Mkandawire [20] and Shin [21] (Table 2). The linear elastic stiffness values of the long/short plantar ligaments and plantar fascia were given by literature [22, 23] (Table 3). The cartilage was defined as being neoHookean hyperelastic with $\mathrm{E}=10 \mathrm{Mpa}$ and $\mathrm{v}=0.45$ [24]. The contact of joints was simulated by adding a surfaceto-surface contact element between the cartilage of joints, with a coefficient of friction $(\mu)$ of 0 . The peroneus brevis tendon used as graft was also considered as a linear elastic material with an elastic modulus value of $\mathrm{E}=$ 149.7 MPa and a cross sectional area of $19.5 \mathrm{~mm}^{2}$ [25]. The hamstring tendon used as graft was assumed as isotropic hyperelastic; its strain energy density function was obtained from a previous paper [26].

The rotational angle of the subtalar joint in inversional test were used for mesh convergence study. In the test, the fibula and tibia were flexed and a rotational moment of $4 \mathrm{Nm}$ was applied on calcaneus about the mediallateral axis. For verification, the element size was varied and the relative change of inversional angle was 

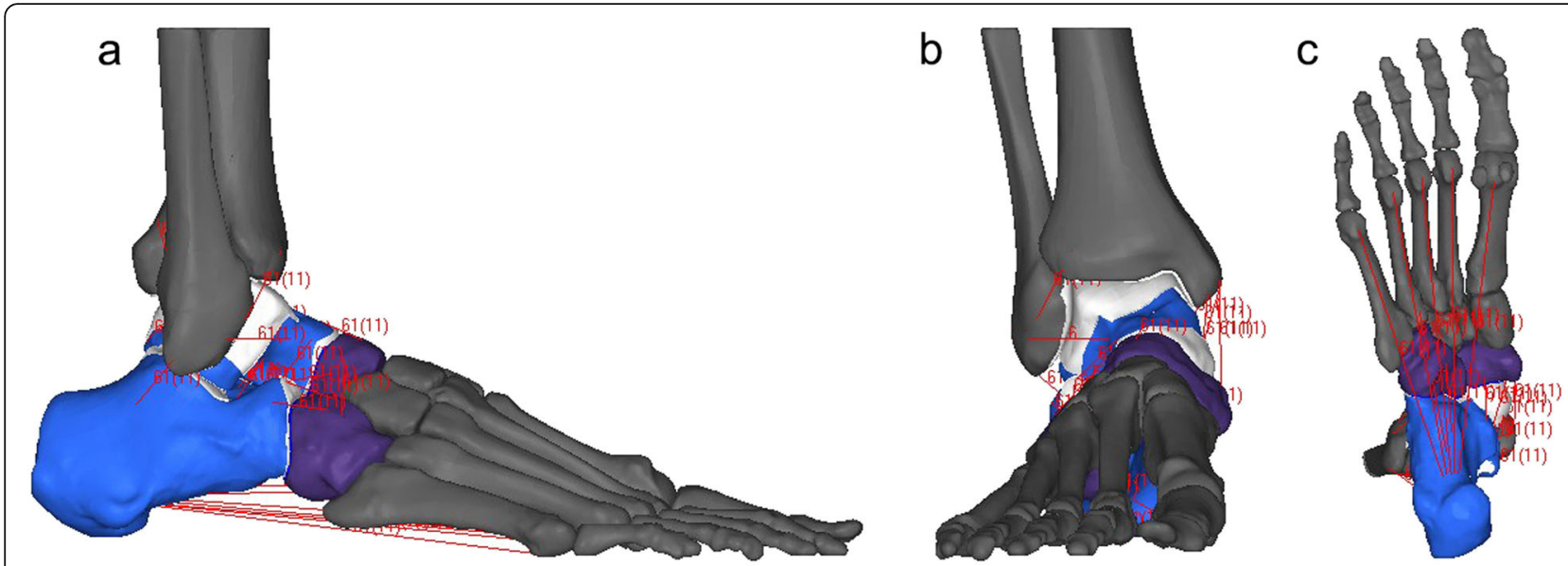

Fig. 1 The FE model: a lateral view, b front view, c bottom view

determined. The trial-error approach was employed in mesh convergence study [27]. Bone meshes with element volume of $35 \mathrm{~mm}^{3}, 11 \mathrm{~mm}^{3}, 1.5 \mathrm{~mm}^{3}$ and cartilage meshes with element volume of $1.5 \mathrm{~mm}^{3}, 0.2 \mathrm{~mm}^{3}, 0.01 \mathrm{~mm}^{3}$ were generated for intact model. Meshes were considered converged when the average change in inversional angle between subsequent meshes was less than $5 \%$. Based on the results of the mesh convergence study, all further analyses were completed with the bones meshes with volume of $1.5 \mathrm{~mm}^{3}$ and cartilage meshes with volume of $0.2 \mathrm{~mm}^{3}$. The final FE model consisted of 178,370 elements and 69,517 nodes.

The subtalar instability was simulated by removing the CFL, ITCL and CL, as suggested by a previous cadaveric study [13]. Due to the fact that subtalar instability rarely occurs alone, the ATFL was further removed before performing the analysis of Schon triligamentous reconstruction and Mann triligamentous reconstruction.

\section{Simulation of subtalar instability and validation}

In previous cadaveric studies, the subtalar instability was usually simulated by sectioning the CFL, CL and ITCL

Table 1 Properties of tibia, fibula and hindfoot ligaments [18, 19]

\begin{tabular}{lll}
\hline Ligament & $\mathbf{a}(\mathbf{N})$ & $\mathbf{b}$ \\
\hline Anterior talofibular & 7.18 & 12.50 \\
Anterior tibiofibular & 5.52 & 22.63 \\
Anterior tibiotalar & 2.06 & 20.11 \\
Calcaneofibular & 0.20 & 49.63 \\
Posterior talofibular & 0.14 & 44.35 \\
Posterior tibiofibular & 6.87 & 20.07 \\
Posterior tibiotalar & 1.34 & 28.65 \\
Tibiocalcaneal & 0.51 & 45.99 \\
Tibionavicular & $\mathrm{k}=39.1 \mathrm{~N} / \mathrm{mm}$ & \\
\hline
\end{tabular}

$[4,13]$. This method was also adopted in our numerical analysis. The model was validated by comparing the results of our numerical analysis with previous experimental data [4, 13]. It was found that the inversion and external rotation of the subtalar joint in the intact/instability model under a torsional moment of $4 \mathrm{Nm}$ were consistent between our simulation and Pellegrini's experiment (Table 4). The inversion under $1.5 \mathrm{Nm}$ and the internal rotation under $3 \mathrm{Nm}$ of the subtalar joint in our simulation were close to Choisne's results (Table 5).

\section{Simulation of tenodesis reconstructions}

Five different types of tenodesis reconstruction were simulated in our FE model. The procedures of Pisani ITCL reconstruction [11], Schon CL reconstruction [12] and Choisne CFL reconstruction [13], which recreated a single ligament in the subtalar joint, were simulated in

Table 2 Properties of hindfoot and midfoot bone ligaments [20, 21]

\begin{tabular}{lll}
\hline Ligament & Area $\left(\mathbf{m m}^{2}\right)$ & Area ratio \\
\hline Anterior talocalcaneal & 14.4 & 0.229 \\
Posterior talocalcaneal & 14.96 & 0.238 \\
Lateral talocalcaneal & 6.84 & 0.109 \\
Medial talocalcaneal & 14.91 & 0.237 \\
Interosseous talocalcaneal & 72.80 & 1.158 \\
Dorsal talonavicular & 35.15 & 0.559 \\
Interosseous calcaneocuboid & 72.80 & 1.158 \\
Plantar calcaneocuboid & 98.70 & 1.570 \\
Inferior calcaneonavicular & 9.23 & 0.147 \\
Superomedial calcaneonavicular & 161.00 & 2.560 \\
Dorsal cuboideonavicular & 13.10 & 0.208 \\
Plantar cuboideonavicular & 27.80 & 0.442 \\
Interosseous cuboideonavicular & 14.01 & 0.223 \\
\hline
\end{tabular}


Table 3 Properties of plantar fascia and long/short plantar ligaments [22, 23]

\begin{tabular}{ll}
\hline Ligament & Stiffness $\mathbf{k}(\mathbf{N} / \mathbf{m m})$ \\
\hline Plantar fascia & 203.3 \\
Long/Short plantar ligament & 75.9 \\
\hline
\end{tabular}

group 1 on a FE model with CFL, CL and ITCL removed. The procedures of Schon triligamentous reconstruction [12] and Mann triligamentous reconstruction [14], which recreated the ATFL, CFL and CL simultaneously, were simulated in group 2 on a FE model with ATFL, CFL, CL and ITCL removed. In clinical approaches, some parts of the graft tendon pass through the bone tunnels in talus, calcaneus and fibula, but this was not simulated in our analysis.

\section{(a) Pisani ITCL reconstruction}

The attachment point of the graft on the bone was determined by clinical approaches [11]. One half-peroneus brevis graft was used in this procedure. A double stranded ITCL was recreated between two calcaneal and two talar tunnels. The part of half-peroneus brevis tendon connecting the fifth metacarpal base with calcaneus was also simulated (Fig. 2a).

\section{(b) Schon $C L$ reconstruction}

This procedure was simulated based on clinical approaches [12],by using one half-peroneus brevis graft. The CL was recreated between the calcaneus and the talar neck. The part of half-peroneus brevis tendon connecting the fifth metacarpal base with calcaneus was also simulated (Fig. 2b).

\section{(c) Choisne CFL reconstruction}

This procedure was simulated based on clinical approaches [13],by using the entire peroneus brevis tendon. The graft passed from the anatomic insertion of CFL on fibula to the attachment on calcaneus (Fig. 2c).

\section{(d) Schon triligamentous reconstruction}

This procedure was simulated based on clinical approaches [12], by using the entire peroneus brevis tendon. The ATFL, CFL and CL were recreated simultaneously. The attachment of the graft on the calcaneus, talus and fibula was set on the native insertion of these ligaments. The part of entire peroneus brevis tendon connecting the fifth metacarpal base and calcaneus was also simulated (Fig. 3a).

\section{(e) Mann triligamentous reconstruction}

This procedure was simulated based on clinical approaches [14], by using the hamstring tendon. The ATFL, CFL and CL were also recreated simultaneously. The attachment of the graft on the bone was the corresponding anatomic insertion of these three ligaments (Fig. 3b).

\section{Boundary conditions}

To simulate different ankle positions in numerical analysis, the loading condition was applied in two steps. First, the fibula and tibia were flexed at $10^{\circ}$ dorsiflexion/ plantarflexion or in the neutral position, while the $6 \mathrm{de}$ grees of freedom of the foot were fixed. Then, the 6 degrees of freedom of the tibia and fibula were fixed too, and a rotational moment of $4 \mathrm{Nm}$ was applied on the bottom of calcaneus about the medial-lateral axis (Fig. 4). The rotational moment was set to $4 \mathrm{Nm}$,which was the same as a previous cadaveric study of subtalar instability [4]. The internal stress in the ligament was considered to be free in the neutral position of the hindfoot. The inversion/eversion and internal/external rotation of the subtalar joint were measured at different ankle positions. The inversional stress test was commonly used in clinical setting for diagnosing the instability of subtalar joint. The biomechanics of subtalar joint under inversional stress was carefully analyzed. The force in ligament and reconstructed grafts of the inversional stress test were calculated. The contact area and pressure of the subtalar joint were also compared. A load of $600 \mathrm{~N}$ was applied on the tibia mimicking the body weight during walking. The loading conditions applied on the model were shown in Fig. 4.

\section{Results}

Group 1

Kinematics of subtalar joint

The section of CFL, ITCL and CL led to obvious instability in the subtalar joint. The inversion, external rotation and internal rotation of the joint all increased at

Table 4 Comparison of inversion (4 Nm) and external rotation (4 Nm) between our simulation and Pellegrini's experiment [4]

\begin{tabular}{llll}
\hline & & Cadaveric model (degrees) & FE model (degrees) \\
\hline Intact & Inversion & $7.2 \pm 1.7$ & 7.0 \\
& External rotation & $4.8 \pm 1.1$ & 4.8 \\
Subtalar instability & Inversion & $12.8 \pm 5.8$ & 12.7 \\
& External rotation & $8.0 \pm 3.5$ & 7.5 \\
\hline
\end{tabular}


Table 5 Comparison of inversion (1.5 Nm) and internal rotation (3 Nm) between our simulation and Choisne's experiment [13]

\begin{tabular}{llll}
\hline & & Cadaveric model (degrees) & FE model (degrees) \\
\hline Intact & Inversion & $7.0 \pm 3.0$ & 6.2 \\
& Internal rotation & $7.2 \pm 3.3$ & 6.7 \\
Subtalar instability & Inversion & $12.2 \pm 3.3$ & 11.3 \\
& Internal rotation & $9.8 \pm 2.5$ & 8.9 \\
\hline
\end{tabular}

different ankle positions (Fig. 5). The eversion, however, showed no markly increase (not shown in figure). All the three procedures improved the stability of subtalar joint in the neutral position, $10^{\circ}$ dorsiflexion and $10^{\circ}$ plantarflexion. The Choisne CFL reconstruction was most effective in stabilizing the joint. The inversion of the subtalar joint under a rotational moment of $4 \mathrm{Nm}$ at the neutral position was $7^{\circ}$ for intact, $12.7^{\circ}$ for unstable, $10.2^{\circ}$ for the Schon, $8.8^{\circ}$ for the Pisani and $7.8^{\circ}$ for the Choisne, respectively (Fig. 5a). The Pisani ITCL reconstruction exhibited the weakest effect in controlling the internal and external rotation. The internal rotation of the calcaneus at the neutral position was $5.5^{\circ}$ for intact, $8.3^{\circ}$ for unstable, $6.6^{\circ}$ for the Schon, $7.6^{\circ}$ for the Pisani and $6.1^{\circ}$ for the Choisne, respectively (Fig. 5b). Although the recreation of CFL restored the kinematics of subtalar joint almost to normal, joint laxity still existed.

\section{The force of ATFL in inversional stress test}

The subtalar stress test was very important for diagnosis of subtalar instability. The force in ATFL in inversional stress test at neutral position was compared and shown in Table 6. In the intact model, the force of ATFL is $180 \mathrm{~N}$. However, for single ligament reconstruction procedures, the force was $158 \mathrm{~N}, 121 \mathrm{~N}$ and $77 \mathrm{~N}$ for CFL, ITCL and CL reconstruction, respectively.

\section{The stress in reconstructed grafts in inversional stress test}

The stress of reconstructed grafts in inversional stress test was shown in Table 7. The reconstructed CFL in Choisne procedure resist greatest stress than the grafts of other 2 procedures. The stress in recreated grafts were obviously greater than corresponding ligaments of the intact model. It suggest that the subtalar ligaments in intact model could withstand the inversional stress together.
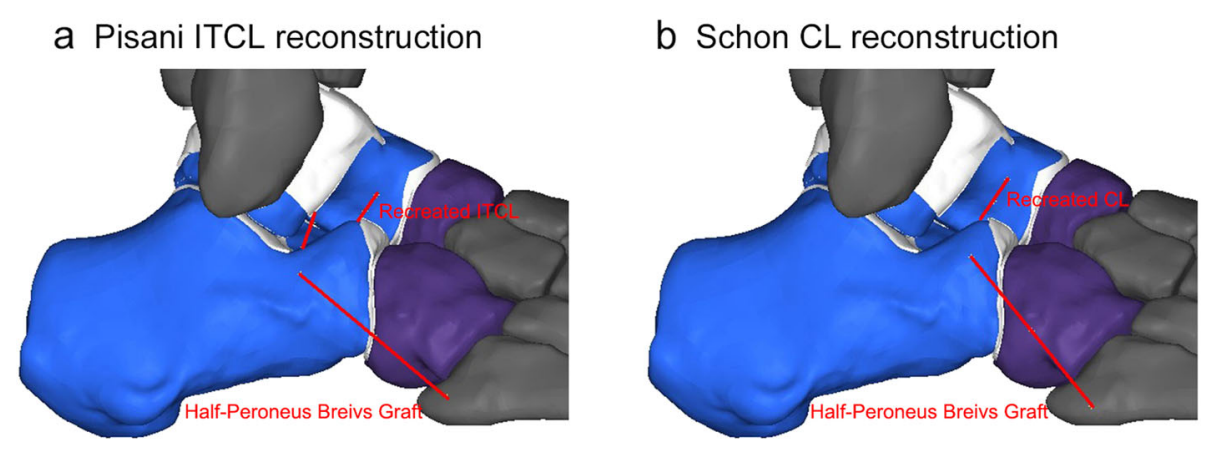

C Choisne CFL reconstruction

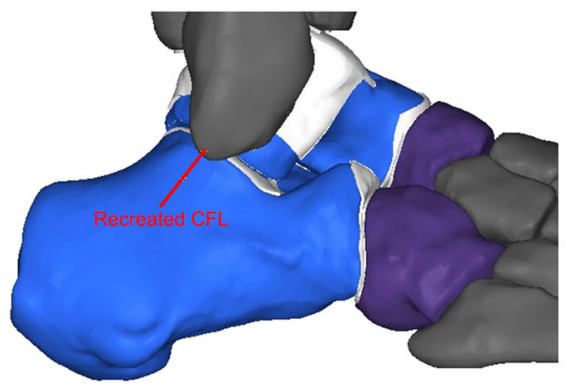

Fig. 2 Single ligament reconstruction: three models with reconstructed tendon grafts: a Pisani ITCL reconstruction by using one half-peroneus brevis graft, $\mathbf{b}$ Schon CL Reconstruction by using one half-peroneus brevis graft, and $\mathbf{c}$ Choisne CFL reconstruction by using entire peroneus brevis tendon 
a Schon triligamentous reconstruction

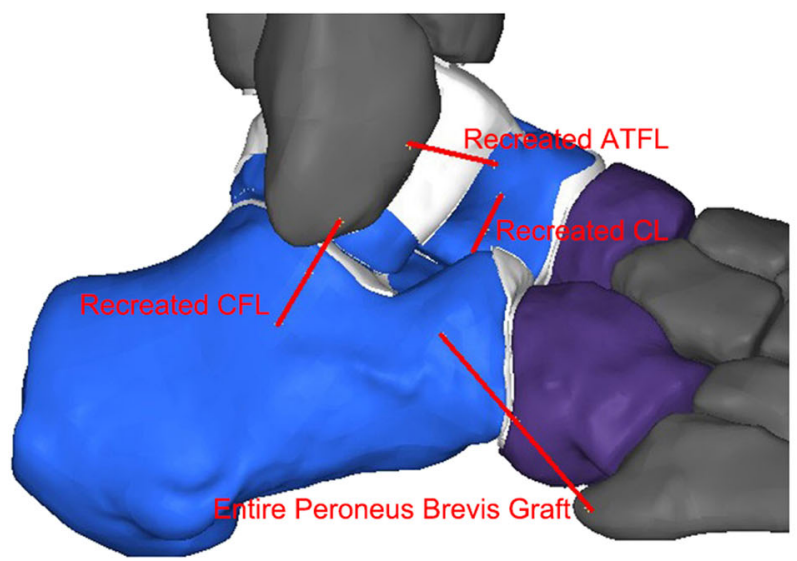

b Mann triligamentous reconstruction

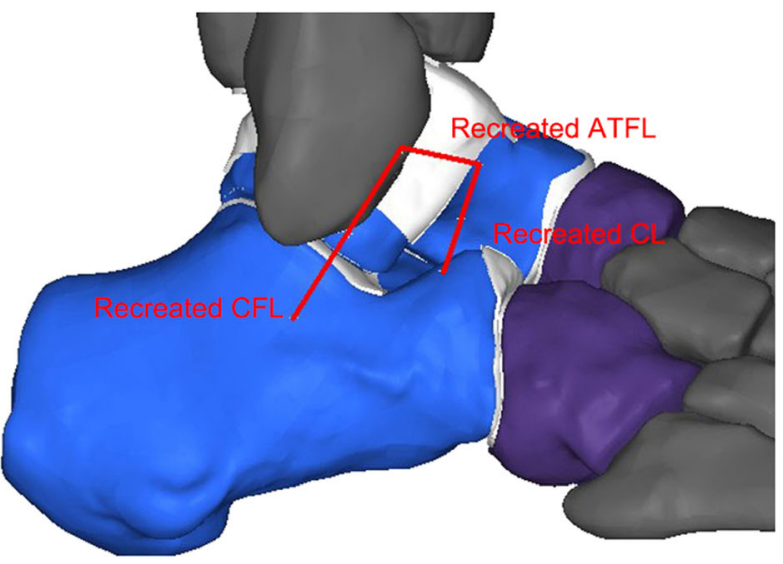

Fig. 3 Triligamentous reconstruction: a Schon triligamentous reconstruction by using entire peroneus brevis tendon, b Mann triligamentous reconstruction by using hamstring tendon

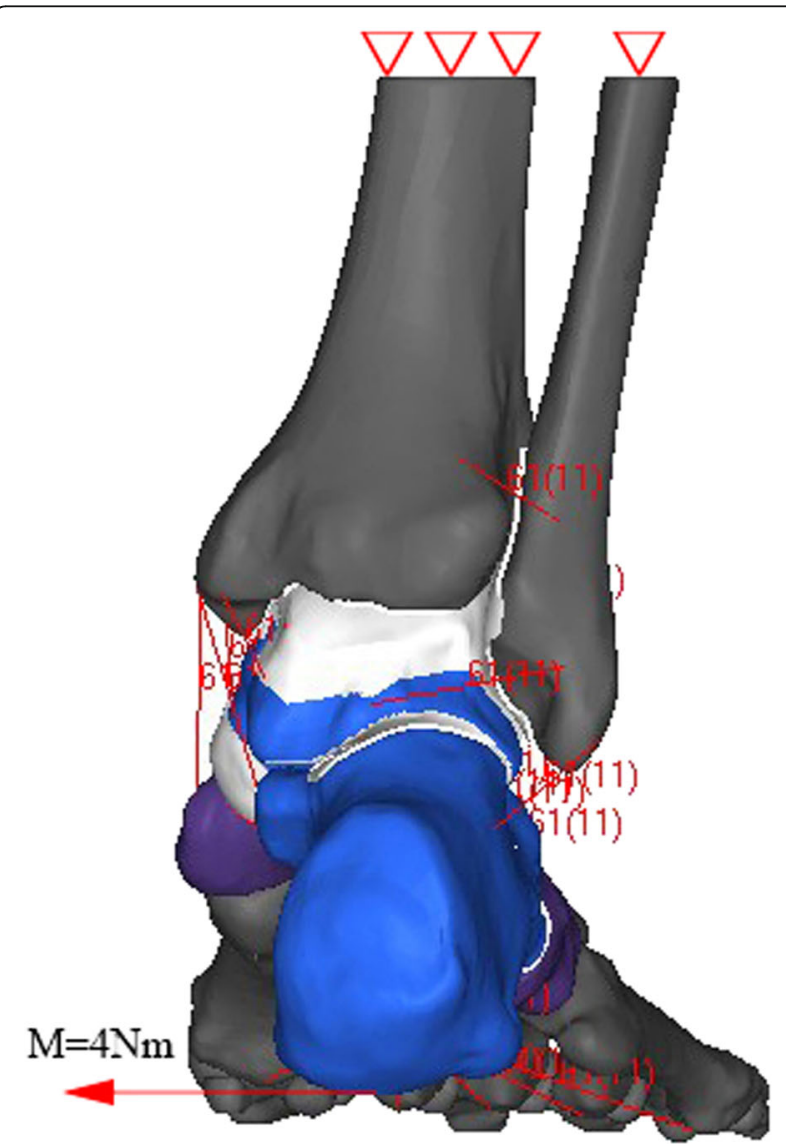

Fig. 4 The boundary conditions of the inversional test. The tibia and fibula was fixed. A inversional moment of $4 \mathrm{~N}$.m was applied on the calcaneus

\section{Group 2}

\section{Kinematics of subtalar joint}

The additional section of ATFL only led to a slight increase of motion in the subtalar joint compared to group 1. Although the Schon and Mann triligamentous reconstructions did not recreate the ITCL, these two procedures improved the joint stability very effectively (Fig. 6). The Mann procedure even over-restrained the motion of subtalar joint at all the three ankle positions (Fig. 6). For example, the inversion of subtalar joint at the neutral position was $14.2^{\circ}$ for unstable, $6.6^{\circ}$ for the Mann and $7.5^{\circ}$ for the Schon, respectively (Fig. 6a). The internal rotation of subtalar joint at neutral position was $9.3^{\circ}$ for unstable, $5.1^{\circ}$ for the Mann and $5.7^{\circ}$ for the Schon, respectively (Fig. 6b).

\section{The stress within the reconstructed grafts}

The triligamentous reconstruction procedures recreated the ATFL, CFL and CL. The stress in the recreated ATFL, CFL and CL were shown in Table 8. The grafts in Mann procedures resist greater stress than the grafts in Schon procedure.

\section{The contact characteristics of subtalar joint}

Firstly, we applied $600 \mathrm{~N}$ vertical force on the tibia and calculated the contact pressure and area in the intact model. The pressure nephogram of the subtalar joint revealed 3 key stress area, corresponding to anterior, middle and posterior part of subtalar joint, respectively (Fig. 7). It suggested that the calcaneus support the upper talus through 3 area, similar to the 3 point load bearing structure. The maximum pressure was highest in anterior subtalar joint. With inversional stress on calcaneus, the overall pressure and the total area for which the load is distributed on posterior subtalar joint 


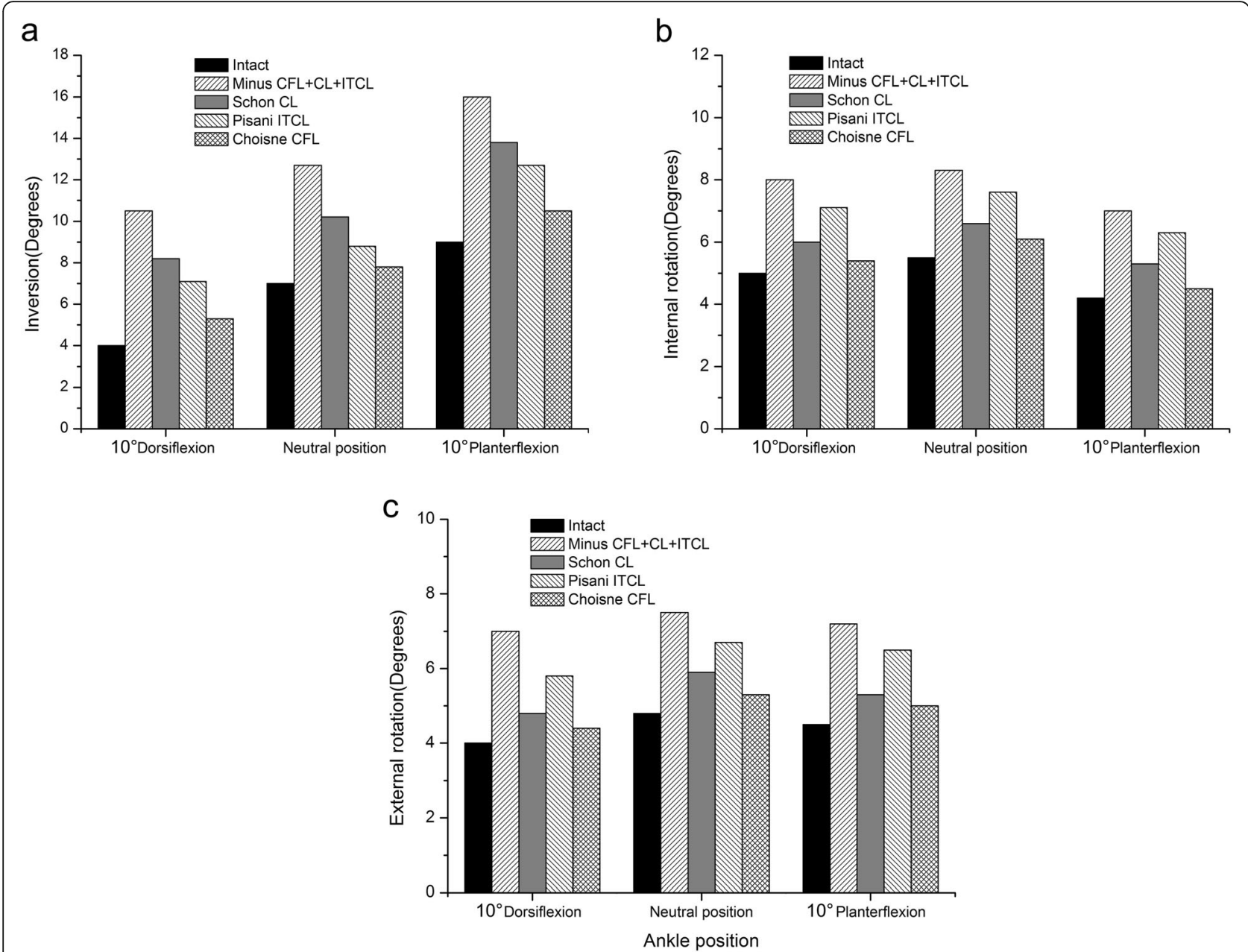

Fig. 5 Range of (a) inversion, (b) internal rotation and (c) external rotation at the subtalar joint in the intact condition; after sectioning the ITCL, $\mathrm{CFL}$ and $\mathrm{CL}$; after performing the Schon CL reconstruction; after performing the Pisani ITCL reconstruction; and after performing the Choisne CFL reconstruction in different ankle position

decreased. However, only the lateral region of the articular surface is out of contact. With 3(CFL, ITCL, and CL) or 4(ATFL, CFL, ITCL, and CL) ligaments removed, the whole posterior articular facet is out of contact. It suggest the that the posterior subtalar joint is dislocated completely. Of the 5 procedures, the contact characteristics of subtalar joint with Mann triligamentous reconstruction was most similar to that of intact model. On the contrary, the similarity between Schon CL reconstruction and the intact model was the worst.

\section{Discussion}

The subtalar joint plays an important role in hindfoot stability. Specifically, the ligamentous contents in the subtalar joint are main structures contributing to its stability. Taillard et al. found that the CFL ruptured first with an inversional force exerted on the cadaveric model, followed by the CL and then the ITCL [28]. Several procedures have been developed for restoring subtalar instability, including CFL reconstruction, CL reconstruction, ITCL reconstruction, and triligamentous reconstruction. However, no comprehensive comparison on their biomechanical behaviors has been conducted yet. In view of this, we compared these 5 representative procedures in this numerical analysis, and the results suggested that the Choisne CFL and Mann triligamentous reconstructions were most effective in stabilizing the subtalar joint.

Table 6 The force of ATFL(N) for 3 single ligament reconstruction procedures in inversional stress test at neutral position

\begin{tabular}{lllll}
\hline & Intact & CFL reconstruction & ITCL reconstruction & CL reconstruction \\
\hline Inversional stress test & 187 & 158 & 121 & 77 \\
\hline
\end{tabular}


Table 7 The stress $(N)$ in reconstructed grafts of 3 single ligament reconstruction and the corresponding ligaments of intact model in inversional stress test at neutral position

\begin{tabular}{llll}
\hline & CFL & ITCL & CL \\
\hline Reconstruction & 304 & 234 & 181 \\
Intact & 238 & 183 & 169 \\
\hline
\end{tabular}

Previous cadaveric studies have compared the stabilizing effect of different subtalar ligaments. However, which ligament contributes the most remains controversial. The objective of the present study was not to examine the effect of injury in one of the mentioned ligaments. Thus, the ITCL, CFL and CL were removed simultaneously to simulate subtalar instability. Nevertheless, the results of different tenodesis reconstructions can reflect the contribution of these ligaments.
Table 8 The stress $(N)$ in recreated ATFL, CFL and CL for 2 triligamentous reconstruction procedures

\begin{tabular}{llll}
\hline & ATFL & CFL & CL \\
\hline Intact & 187 & 238 & 169 \\
Schon procedures & 168 & 209 & 133 \\
Mann procedures & 198 & 234 & 167 \\
\hline
\end{tabular}

Pisani stressed the importance of ITCL and developed a procedure to recreate the ITCL in1996 [11]. A onehalf peroneus brevis graft is woven through two calcaneal and two talar tunnels to recreate ITCL. ITCL is a $\mathrm{V}$-shaped ligament composed of two bands, with the fiber oriented from superomedial to inferolateral [17]. It occupies nearly half of the medial part of the tarsal canal. There is still no agreement regarding the mechanical contribution of ITCL to subtalar instability. Some a

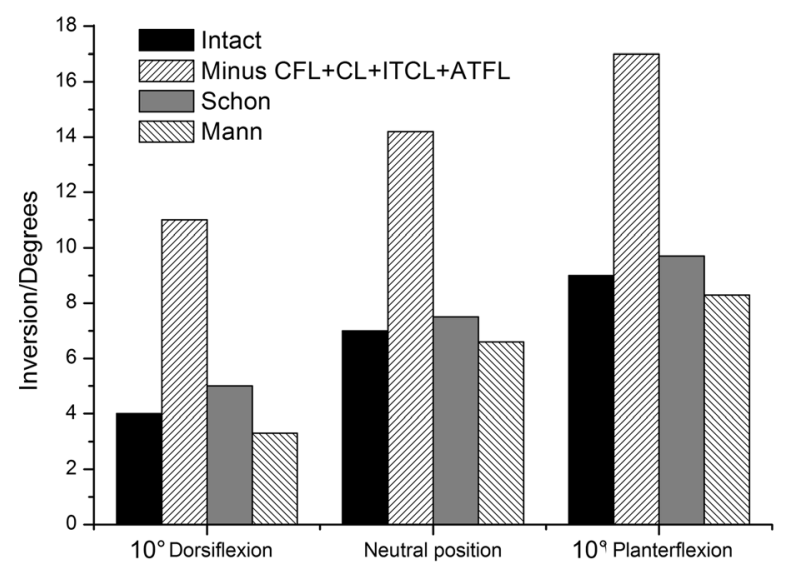

b

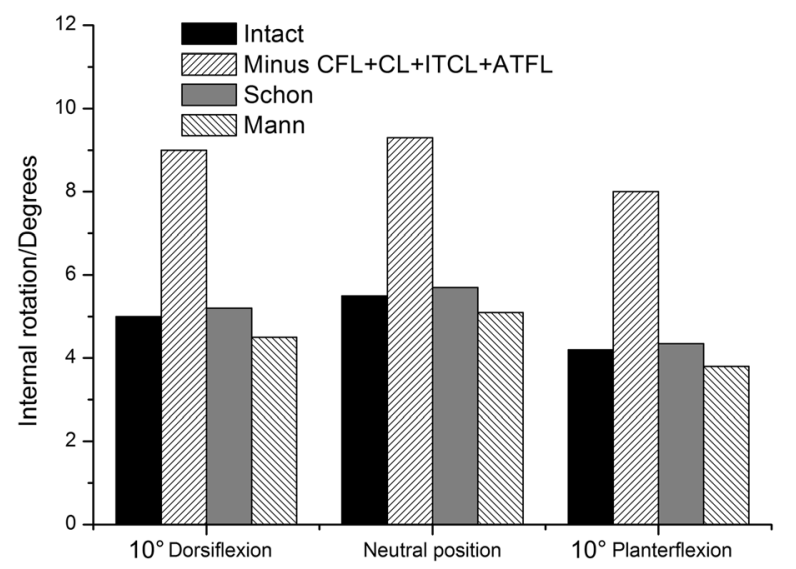

C

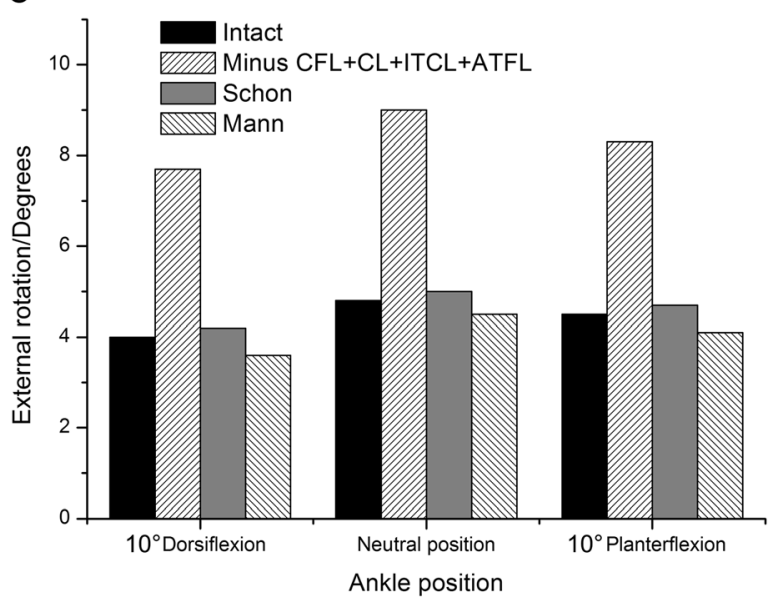

Fig. 6 Range of (a) inversion, (b) internal rotation and (c) external rotation at the subtalar joint in the intact condition; after sectioning the ATFL, $\mathrm{ITCL}, \mathrm{CFL}$ and $\mathrm{CL}$; after performing the Schon triligamentous reconstruction; and after performing the Mann triligamentous reconstruction in different ankle position 


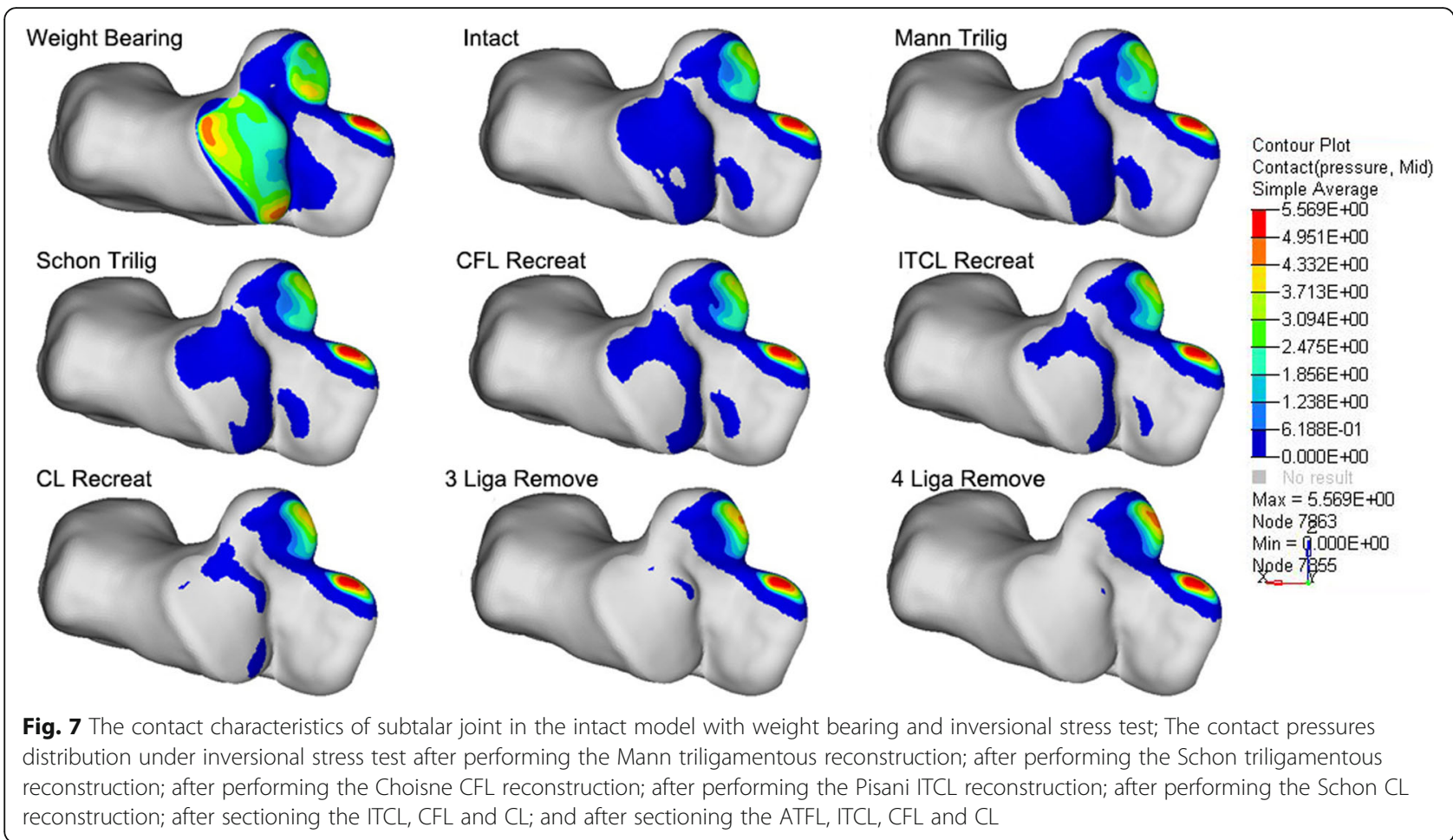

researchers compared it with the cruciate ligaments of the knee in terms of the stabilizing effect on the subtalar joint $[11,29]$. Knudson reported that the ITCL contributed substantially to supination stability [30]. Tochigi et al. suggested that the ITCL restrained the subtalar joint in inversion and prevented anteromedial displacement [31]. However, several publications questioned the importance of the ITCL $[4,6]$. For example, Li et al. pointed out that the most important ligament of the tarsal sinus was the CL, while the ITCL, although always present, was a thin single-band ligament [32]. Smith and Cahill $[33,34]$ highlighted that the ITCL was not an important component for subtalar stability. In our simulation, the Pisani ITCL reconstruction was found to reinforce the inversional stability, but had little effect on rotational stability. Tochigi suggested that the ITCL counteracted against the drawer force on the calcaneus [31]. The ITCL was located between the posterior and middle facet of the subtalar joint, similar to the cruciate ligaments of the knee. The cruciate ligaments mainly restrain the anterior and posterior translation of the tibia. Similarly, the ITCL may primarily restrain the translational displacement of calcaneus, but contribute little to rotational stability.

The Schon CL reconstruction was developed in 1991 [12]. One-half peroneus brevis tendon was used in this procedure. Schon believed this procedure was appropriate for mid-to-moderate subtalar instability. The CL is another important ligament of the subtalar joint. Its fiber is oriented from the superolateral calcaneal surface to an inferolateral tubercle on the talus neck. Some researchers believed that the CL was more important than the ITCL in stabilizing the subtalar joint [2, 3, 32]. Earlier studies found that the CL could restrain the inversion and external rotation of the subtalar joint [7, 33, 34]. Our study also revealed that the Schon CL reconstruction contributed more to the rotational stability than the ITCL reconstruction did, but its effect on inversional stabilization was the weakest of the three procedures.

Choisne described a tenodesis reconstruction procedure to recreate the CFL in 2016 [13]. The entire peroneus brevis tendon was used in this procedure. The CFL originates from the fibular tip to the lateral posterior calcaneus and bridges the posterior facet of the subtalar joint subtalar joint. It is widely accepted as an important ligament for ankle stabilization, and its function in relation to subtalar stability has been gradually revealed and confirmed in recent years. Weindel and Karlsson supposed that the CFL played a key role in subtalar stability $[3,6]$. Choisne et al. reported that subtalar instability occurred after section of CFL in isolation in their experiment [35]. Pellegrini et al. found that the CFL disruption could lead to an increase in inversion and external rotation, which might be detectable during a manual examination [4]. Our study showed that the Choisne CFL reconstruction was more effective than the Pisani ITCL and Schon CL reconstructions in alleviating the instability of subtalar joint. However, the Choisne CFL 
reconstruction needs to use the entire peroneus brevis tendon as graft, while the Pisani ITCL and Schon CL reconstructions use only half of a peroneus brevis tendon. This may enhance the stabilizing effect of Choisne CFL reconstruction.

After a comparison of these three procedures, we found that the stress in reconstructed grafts of the 3 single ligament reconstruction all increased compared to the corresponding ligament of intact model in inversional test. On the contrary, the force of ATFL in reconstructed models all decreased. It suggest the reconstructed grafts withstood more stress than the normal ligament. In the long term, these grafts may not be able to withstand the increased internal stress.

For subtalar instability usually coexists with lateral ankle instability $[1,2]$, the triligamentous reconstruction procedure was developed for recreating the ATFL, CFL and CL. Schon et al. described a triligamentous reconstruction [12]. The entire peroneus brevis is weaved through 4 bone tunnels to recreate the CFL, ATFL and CL. Thomas et al. described a triligamentous reconstruction in Mann's surgery of the foot and ankle [14]. This technique was designed to correct symptomatic severe subtalar instability with a hamstring tendon graft. In our simulation, the triligamentous reconstruction improved the subtalar stability very effectively without recreating the ITCL. The contact characteristics of the subtalar joint and the stress of grafts in Mann triligamentous reconstruction was more similar to the intact model. The results showed that the Mann procedure had a stronger correcting power in controlling subtalar instability than the Schon procedure did. This may be attributed to the difference in their grafts. The elastic modulus and crosssectional area of semitendinosus are $1036 \mathrm{MPa}$ and $20 \mathrm{~mm}^{2}$, respectively [36, 37]. The peroneus brevis tendon has an elastic modulus value of $149.7 \mathrm{MPa}$ and a cross-sectional area of about $19.5 \mathrm{~mm}^{2}$ [25]. Obviously, the strength of semitendinosus is much higher than that of peroneus brevis tendon. However, according to our simulation results, the hamstring tendon is so stiff that it restrains the mobility of the subtalar joint. This might result in detrimental long-term effects on the cartilage [38]. The increased internal stress in the subtalar joint could accumulate over time, ultimately leading the cartilage degeneration and hind foot stiffness. On the other hand, the peroneus brevis tendon is too elastic for the subtalar joint and the model remains a certain degree of laxity under the Schon procedure. The ideal graft should have the same material properties as the native ligament and mimic the same biomechanical behaviors as the original joint [36]. Therefore, both types of graft have defects.

In general, although several experiments have evaluated the biomechanical function of subtalar ligaments, the conclusions remain controversial. Therefore, there is no consensus on which ligament should be recreated first by the tenodesis procedure. At the same time, the injury mechanism and clinical manifestation of subtalar instability are similar to that of ankle instability, and therefore, its diagnosis is often misinterpreted. As a result, the publications of surgical reconstruction regarding subtalar instability are very limited. In addition, most of these studies are retrospective case series with limited numbers of patients [9, 11-13, 29]. Thomas et al. [39] has summarized the results of these reports. The results showed that their clinical results seem to be similar. On the other side, there is no comprehensive comparison targeting the correcting power of these tenodesis procedures so far. The results of our study showed that none of these tenodesis procedures could restore the biomechanical behaviors of the subtalar joint to normal. Fortunately, the stability of subtalar joint was supported by the bony geometry and ligaments jointly. In a cadaveric research on hindfoot stability, Cass et al. found that the subtalar joint appeared to be stable when the foot was loaded, and they believed that the stability of subtalar joint largely came from the bony constrains [40]. In our simulation, the subtalar joint in rotational test was loaded without weight bearing. In this condition, the tested procedures still managed to restore the subtalar stability effectively. Even though the joint was subject to a certain degree of laxity with these procedures, with the inherent stability of the joint surface congruency, the subtalar instability would be further improved in weight bearing.

There are several limitations in the present study. First, some simplifications were introduced in our model. The material properties of the ligaments and grafts were determined in accordance with the literature rather than actual measurements. Different material models were used for soft tissues, including both linear hyperelastic and non-linear hyperelastic models, and the viscoelastic properties of the soft tissues were not considered. These data from published literatures introduced uncertainty to this study. And, some parts of the grafts that pass through the bone tunnels were also simplified. This may also affect the forces within the ligaments. Despite these simplifications, the validation test showed that our simulation results were very close to the experimental measurements of previous cadaveric studies. Second, our FE model was only simulated based on an young male volunteer. However, the validation comparator used were cadaver specimens from old male and female person. Therefore, when we use the conclusion of this article, was must take note of its applicability. Moreover, only one model was simulated in this study. However, the contact mechanics and contact patterns would vary from person to person. Therefore, 
subject-specific finite element models were needed to improve the accuracy of our analysis in future.

\section{Conclusion}

In the present study, our numerical analysis showed that the Choisne CFL reconstruction and Mann triligamentous reconstruction were most effective in restoring the kinematics and contact stress distribution in the subtalar joint. However, both procedures could not restore the biomechanical behaviors of the subtalar joint to normal. This study provided a greater understanding of the biomechanical response of ligament reconstruction in subtalar instability. The efficacy of these procedures will be investigated in a substantial number of patients with a long-term follow-up period and optimal procedures for the patients will be developed.

\section{Abbreviations}

ITCL: Interosseous talocalcaneal ligament; CL: Cervical ligament; CFL: Calcaneofibular ligament; ATFL: Anterior talofibular ligament; NURBS: Non-uniform rational B-spline; CT: Computerized tomography; MRI: Magnetic resonance imaging

\section{Acknowledgements}

Not Applicable.

\section{Consent to publish}

The patient provided written informed consent for the publication of potentially identifying images and clinical details.

\section{Authors' contributions}

CX performed the finite element analysis, MQL and CGW are responsible for manuscript writing, and $\mathrm{HL}$ contributed for the experimental design and manuscript revision. All authors have read and approved the final manuscript.

\section{Authors' information}

All authors come from the Department of Orthopaedic Surgery, Xiangya Hospital, the Central South University, No. 87, Xiangya Street, Changsha 401008, China.

\section{Funding}

This study was supported by the Natural Science Foundation Project of China (No. 81301543).

\section{Availability of data and materials}

The datasets used and analysed during the current study are available from the corresponding author on reasonable request.

\section{Ethics approval and consent to participate}

The study had been approved by Ethics Committee of Xiangya Hospital (No.202002010) and a written consent was obtained from the participant in CT acquisition

\section{Competing interests}

All authors declare that they have no competing interests.

Received: 5 April 2020 Accepted: 1 October 2020

Published online: 10 October 2020

\section{References}

1. Hertel J. Functional anatomy, Pathomechanics, and pathophysiology of lateral ankle instability. J Athl Train. 2002;37(4):364-75.

2. Meyer JM, Garcia J, Hoffmeyer P, Fritschy D. The subtalar sprain. A roentgenographic study. Clin Orthop Related Res. 1988;226:169-73.
3. Karlsson J, Eriksson BI, Renstrom PA. Subtalar ankle instability. A review. Sports Med (Auckland, NZ). 1997;24(5):337-46.

4. Pellegrini MJ, Glisson RR, Wurm M, Ousema PH, Romash MM, Nunley JA 2nd, Easley ME. Systematic quantification of stabilizing effects of Subtalar joint soft-tissue constraints in a novel cadaveric model. J Bone Joint Surg Am. 2016;98(10):842-8.

5. Tochigi Y, Takahashi K, Yamagata M, Tamaki T. Influence of the interosseous talocalcaneal ligament injury on stability of the ankle-subtalar joint complex--a cadaveric experimental study. Foot Ankle international. 2000; 21(6):486-91.

6. Weindel S, Schmidt R, Rammelt S, Claes L, Campe VA, Rein S. Subtalar instability: a biomechanical cadaver study. Arch Orthop Trauma Surg. 2010; 130(3):313-9.

7. Kjaersgaard-Andersen P, Wethelund JO, Helmig P, Soballe K. The stabilizing effect of the ligamentous structures in the sinus and canalis tarsi on movements in the hindfoot. An experimental study. Am J Sports Med. 1988; 16(5):512-6.

8. Elmslie RC. Recurrent subluxation of the ankle-joint. Ann Surg. 1934;100(2) 364-7.

9. Chrisman OD, Snook GA. Reconstruction of lateral ligament tears of the ankle. An experimental study and clinical evaluation of seven patients treated by a new modification of the Elmslie procedure. J Bone Joint Surg Am. 1969;51(5):904-12.

10. Brattstrom $\mathrm{H}$. Tenodesis employing the method of Watson-Jones for the treatment of recurrent subluxation of the ankle. Acta Orthop Scand. 1953; 23(2):132-6.

11. Pisani G. Chronic laxity of the subtalar joint. Orthopedics. 1996;19(5):431-7.

12. Schon LC, Clanton TO, Baxter DE. Reconstruction for subtalar instability: a review. Foot Ankle. 1991;11(5):319-25.

13. Choisne J, Hoch MC, Alexander I, Ringleb SI. Effect of direct ligament repair and Tenodesis reconstruction on simulated Subtalar joint instability. Foot Ankle Int. 2017:38(3):324-30.

14. Thomas O. Clanton, Waldrop NE: Athletic Injuries to the Soft Tissues of the Foot and Ankle. In: Mann's Surgery of the Foot and Ankle. Volume 2, 9. Coughlin MJ, Saltzman CL, Anderson RB: Mosby; 2013: 1607.

15. Xu C, Li MQ, Wang C, Liu H. Nonanatomic versus anatomic techniques in spring ligament reconstruction: biomechanical assessment via a finite element model. J Orthop Surg Res. 2019:14(1):114.

16. Golano P, Vega J, de Leeuw PA, Malagelada F, Manzanares MC, Gotzens V, van Dijk CN. Anatomy of the ankle ligaments: a pictorial essay. Knee Surg Sports Traumatol Arthroscopy. 2016;24(4):944-56.

17. Kelilian AS. SK S: Sarrafian's anatomy of the foot and ankle. Philadelphia: Wolters Klover Health, LWW; 2011.

18. Funk JR, Hall GW, Crandall JR, Pilkey WD. Linear and quasi-linear viscoelastic characterization of ankle ligaments. J Biomech Eng. 2000;122(1):15-22.

19. Siegler S, Chen J, Schneck CD. The three-dimensional kinematics and flexibility characteristics of the human ankle and subtalar joints--part l: kinematics. J Biomech Eng. 1988;110(4):364-73.

20. Mkandawire C, Ledoux WR, Sangeorzan BJ, Ching RP. Foot and ankle ligament morphometry. J Rehabil Res Dev. 2005;42(6):809-20.

21. Shin J, Yue N, Untaroiu CD. A finite element model of the foot and ankle for automotive impact applications. Ann Biomed Eng. 2012;40(12):2519-31.

22. Cheung JT, An KN, Zhang M. Consequences of partial and total plantar fascia release: a finite element study. Foot Ankle Int. 2006;27(2):125-32.

23. Kitaoka HB, Luo ZP, Growney ES, Berglund LJ, An KN. Material properties of the plantar aponeurosis. Foot Ankle Int. 1994;15(10):557-60.

24. Anderson $A E$, Ellis BJ, Maas SA, Peters CL, Weiss JA. Validation of finite element predictions of cartilage contact pressure in the human hip joint. Biomech Eng. 2008;130(5):051008

25. Bohnsack M, Surie B, Kirsch IL, Wulker N. Biomechanical properties of commonly used autogenous transplants in the surgical treatment of chronic lateral ankle instability. Foot Ankle Int. 2002;23(7):661-4

26. Weiss JA, Gardiner JC, Bonifasi-Lista C. Ligament material behavior is nonlinear, viscoelastic and rate-independent under shear loading. J Biomech. 2002;35(7):943-50.

27. Burkhart TA, Andrews DM, Dunning CE. Finite element modeling mesh quality, energy balance and validation methods: a review with recommendations associated with the modeling of bone tissue. J Biomech. 2013;46(9):1477-88.

28. Taillard W, Meyer JM, Garcia J, Blanc Y. The sinus tarsi syndrome. Int Orthop. 1981:5(2):117-30. 
29. Pisani G, Pisani PC, Parino E. Sinus tarsi syndrome and subtalar joint instability. Clinics Podiatric Medicine Surgery. 2005;22(1):63-77.

30. Knudson GA, Kitaoka HB, Lu C-L, Luo ZP, An K-N. Subtalar joint stability: Talocalcaneal interosseous ligament function studied in cadaver specimens. Acta Orthop Scand. 1997;68(5):442-6.

31. Tochigi Y, Amendola A, Rudert MJ, Baer TE, Brown TD, Hillis SL, Saltzman CL. The role of the Interosseous Talocalcaneal ligament in Subtalar joint stability. Foot Ankle Int. 2004;25(8):588-96.

32. Li SY, Hou ZD, Zhang P, Li HL, Ding ZH, Liu YJ. Ligament structures in the tarsal sinus and canal. Foot Ankle Int. 2013;34(12):1729-36.

33. Cahill DR. The anatomy and function of the contents of the human tarsal sinus and canal. Anat Rec. 1965;153(1):1-17.

34. Smith JW. The ligamentous structures in the canalis and sinus tarsi. J Anat. 1958:92(4):616-20.

35. Choisne J, Hoch MC, Bawab S, Alexander I, Ringleb SI. The effects of a semirigid ankle brace on a simulated isolated subtalar joint instability. J Orthop Res. 2013:31(12):1869-75.

36. Smeets K, Bellemans J, Scheys L, Eijnde BOOT, Claes S. Mechanical Analysis of Extra-Articular Knee Ligaments. Part two: Tendon grafts used for knee ligament reconstruction. Knee. 2017;24:5.

37. Handl M, Drzík M, Cerulli G, Povysil C, Chlpík J, Varga F, Amler E, Trc T. Reconstruction of the anterior cruciate ligament: dynamic strain evaluation of the graft. Knee Surgery Sports Traumatology Arthroscopy Official Journal of the Esska. 2007;15(3):233-41.

38. Fu FH, Herbst E. Editorial commentary: the pivot-shift phenomenon is multifactorial. Arthroscopy J Arthroscopic Related Surgery. 2016;32(6):10634.

39. Mittlmeier T, Rammelt S. Update on Subtalar joint instability. Foot Ankle Clin. 2018;23(3):397-413.

40. Cass JR, Morrey BF, Chao EY. Three-dimensional kinematics of ankle instability following serial sectioning of lateral collateral ligaments. Foot Ankle. 1984;5(3):142-9.

\section{Publisher's Note}

Springer Nature remains neutral with regard to jurisdictional claims in published maps and institutional affiliations.

Ready to submit your research? Choose BMC and benefit from:

- fast, convenient online submission

- thorough peer review by experienced researchers in your field

- rapid publication on acceptance

- support for research data, including large and complex data types

- gold Open Access which fosters wider collaboration and increased citations

- maximum visibility for your research: over $100 \mathrm{M}$ website views per year

At $\mathrm{BMC}$, research is always in progress.

Learn more biomedcentral.com/submissions 